\title{
Effect of sample thickness on the structural and optical properties of Polyvinyl Chloride/Zinc Oxide Nanocomposite Films for photocatalysis application
}

aimane guedri ( $\square$ aimaneguedri@gmail.com )

Université d'Oum El Bouaghi - Larbi Ben M'hidi https://orcid.org/0000-0003-0653-4049

Mourad ZAABAT

Université d'Oum El Bouaghi - Larbi Ben M'hidi

Boubekeur BOUDINE

Université des frères Mentouri Constantine 1

Abdelkader HAFDALLAH

Université Larbi Tebessi

\section{Research Article}

Keywords: ZnO nanoparticles, Sol-gel, Polyvinyl chloride (PVC), Layers, Photocatalytic

Posted Date: August 18th, 2021

DOI: https://doi.org/10.21203/rs.3.rs-811397/v1

License: (c) (i) This work is licensed under a Creative Commons Attribution 4.0 International License.

Read Full License 


\title{
Effect of sample thickness on the structural and optical properties of Polyvinyl Chloride/Zinc Oxide Nanocomposite Films for photocatalysis application.
}

\author{
Aimane GUEDRI ${ }^{1}$; Mourad ZAABAT ${ }^{1}$; Boubekeur BOUDINE ${ }^{2}$; Abdelkader HAFDALLAH $^{3}$ \\ 1(LCAM) Laboratoire des composants actifs et matériaux, Université d'Oum El Bouaghi - \\ Larbi Ben M'hidi, 04000 Oum El Bouaghi - Algérie \\ ${ }^{2}$ Laboratoire de cristallographie, Université des frères Mentouri Constantine 1, Route Ain El \\ Bey - Constantine 25000 Algérie \\ ${ }^{3}$ (LPAT) Laboratoire de physique théorique et appliquée, Université Larbi Tebessi - Tebessa, \\ 12002 Tebessa, Algérie \\ aimaneguedri@gmail.com
}

\begin{abstract}
Considered Technique spin coating of the most important techniques used to prepare thin films because it is easy to use and inexpensive since it is closely dependent on the number of layers deposited. This work aims to study the effect of samples thickness for nanocomposites of polyvinyl chloride doped with zinc oxide nanoparticles on the structural, optical properties, and photocatalytic activities. Nanocomposite films of polyvinyl chloride (PVC) - zinc oxide (ZnO) with a different number of the deposited layers $(15,20,25$, and 30 layers) were synthesized by a sol-gel method (spin coating) using tetrahydrofuran as a solvent, and investigated by various techniques. X-ray diffraction measurements indicated in the case of 15, 20, and 25 layers do not clearly show the presence of diffraction peaks. On the other hand, in the case of 30 layers, the presence of several peaks is observed, which testify to the presence of $\mathrm{ZnO}$ crystallites of wurtzite structure in PVC films. The size of the crystallites is almost equal to $32 \mathrm{~nm}$ depending on the working conditions. Raman and infrared spectra confirmed the result of X-ray diffraction on the incorporation of $\mathrm{ZnO}$ crystallites in the films produced by showing peaks corresponding to the modes of vibration of the crystal lattice of the $\mathrm{ZnO}$ doping semiconductor. Optical transmittance spectra have shown that The layers obtained have an optical transmission varying from 75 to $86 \%$ in the visible region of the spectrum. The values of the band gap energies, determined from the transmission spectra for the films deposited on glass, vary between 3.45 and $3.94 \mathrm{eV}$. The Photoluminescence spectra of $\mathrm{ZnO} / \mathrm{PVC}$ nanocomposites studied revealed a strong ultraviolet and green luminescence, attributed to structural defects in the zinc oxide. The photocatalytic reaction has been shown using MB in the UV irradiation action of films stacked in an MB solution. The result showed that the 30-layer (PVC / ZnO) sample gave an efficiency to remove MB of $79 \%$ at $60 \mathrm{~min}$, Similar to other samples which gave a lower efficiency.
\end{abstract}

Keywords : ZnO nanoparticles $\cdot$ Sol-gel $\cdot$ Polyvinyl chloride $($ PVC) $\cdot$ Layers $\cdot$ Photocatalytic 


\section{Introduction}

The study of matter at the nanoscale has been the subject of an increasing number of studies since the second half of the 20th century, due to technological advances in the elaboration and characterization of nanomaterials. Nanocomposites are materials that have a dispersed phase with particles of at least one of the three dimensions on the order of a nanometer $\left(10^{-9}\right.$ meters $)$ or a few tens of nanometers at most $[1,2]$. Thanks to the surface and/or size effects generated by the miniaturization of the particles, nanocomposites can exhibit improved properties compared to conventional composites such as electrical conductivity [3], mechanical strength [4], as well as various optical properties [4]. The size of the nanoparticles also allows the material to retain its original optical properties (e.g. transparency) as well as a good surface finish. Nanocomposites thus offer numerous perspectives for new applications in fields as varied as sensors [5], microelectronics, photocatalysis, photovoltaic cells [6], nonlinear optics, and photonics [7].

Important investigations are focused on II-VI semiconductor nanocrystals due to their large gap which makes them preferred materials for many applications in nanotechnology: highperformance light-emitting diodes, new types of lasers for quantum computing, photodetectors, biological markers, optical memories, photoluminescent devices [8-10]. Due to their promising applications especially in optoelectronics, $\mathrm{ZnO}$ semiconductor is the most studied semiconductor of this family [11-14]. $\mathrm{ZnO}$ is a potential candidate for short wavelength (UV) emitting systems because it has interesting characteristics: a wide band gap (3.37 eV), a large exciton binding energy (60 meV), and a low optical pumping threshold at room temperature $[\mathbf{1 5 , 1 6}]$. These interesting optical properties of semiconductor nanomaterials are mainly due to the effect of charge carrier confinement, which is responsible for the optical emission shift towards short wavelengths [17-22]. It is therefore possible to fabricate optical systems emitting excitations of increasingly smaller wavelengths by further decreasing the size of the semiconductor nanocrystals.

The methods followed for the elaboration of nanomaterials are generally expensive and require sophisticated equipment [23]. With the development of chemical synthesis techniques in the 1990s, the elaboration of nanocrystals has progressed greatly by fabricating nanocrystals with variable geometries and low size dispersions [24]. The use of nanocrystals often requires material supports such as substrates of different shapes or matrices of varying chemical composition [25-29]. To master these new chemical methods of nanomaterials elaboration and to establish the optimal experimental conditions to obtain nanocomposites possessing intense optical activity in the ultraviolet-visible range, we have undertaken the present work which consists of elaborating and characterizing nanocomposites based on the large gap semiconductors $\mathrm{ZnO}$. 
In this work, the soft chemistry method was used to enhance the optoelectronic properties of $\mathrm{PVC} / \mathrm{ZnO}$ nanocomposites thin films. The coating solutions were prepared using $\mathrm{ZnO}$ nanoparticles as doping and PVC as the host's matrix. PVC / ZnO nanocomposites thin films were deposited on cleaned glass substrates by the spin coating technique. Structural, optical properties, and photocatalytic activities of $\mathrm{ZnO}$ thin films were investigated. The effect of nature and the number of layers deposited on optical properties were too studied.

\section{Experimental Details}

$>$ A known amount $(1 \mathrm{~g})$ of polyvinyl chloride was dissolved in $20 \mathrm{ml}$ tetrahydrofuran (THF) as a solvent and stirred by a magnetic stirrer for about $6 \mathrm{~h}$ at $50{ }^{\circ} \mathrm{C}$ to form a homogeneous solution. The part of this solution is used for the preparation of the undoped thin films (pure polymer) which will serve as control samples.

$>$ The $\mathrm{ZnO}$ nanoparticles are poured into $10 \mathrm{ml}$ of tetrahydrofuran (THF) and the mixture is kept under magnetic stirring until a homogeneous solution is obtained. The solution is left to rest so that the relatively bulky nanocomposites settle under the effect of gravity at the bottom of the solution. Finally, the upper part of this solution, containing the smaller nanocomposites, is recovered for doping.

$>$ The final solution used for the preparation of thin films of polyvinyl chloride (PVC) doped with $\mathrm{ZnO}$ nanoparticles with constant concentration (6\%) is obtained by adding the two previous solutions solvent/PVC and solvent/ZnO in well-defined proportions (PVC /6\% ZnO, the proportion in weight are $1 \mathrm{~g}$ of $\mathrm{PVC}$ with $0.06 \mathrm{~g} \mathrm{ZnO}$ in $30 \mathrm{ml}$ of THF). The resulting mixture is kept stirring at $50{ }^{\circ} \mathrm{C}$ to obtain a homogeneous solution.

After obtaining a homogeneous solution, the thin layers are deposited on clean glass substrates by the spin coating technique, with changing each time the number of deposited layers $(15,20,25$, and 30 layers). All the samples were further dried in a vacuum oven before the measurements.

\section{Results and Discussion}

\section{1. $\mathrm{X}$-ray analysis of $\mathrm{ZnO} / \mathrm{PVC}$ nanocomposites}

X-ray diffraction measurements were conducted to examine the nature of crystallinity of the polymer films with respect to pure PVC and to investigate the occurrence of complexation between the polymer and the filler. Figure 1 represents respectively the XRD for pure $\mathrm{ZnO}$ nanoparticles, pure polyvinyl chloride, and doped with $6 \% \mathrm{ZnO}$ nanocomposites at depositing different layers $(15,20,25$, and 30 layers), which were obtained by the spin coating method.

In Figure 1a, we observe a weak broadening of the diffraction peaks, which is due to the nanoscale, grains size of $\mathrm{ZnO}$ powder. 
In Figure 1b:

$>$ In the diagram of pure PVC, we observe the absence of diffraction peaks showing the amorphous state of polyvinyl chloride.

In the diagram of 15,20 and 25 layers does not clearly show the presence of diffraction peaks. This absence of peaks is probably due to the small amount of $\mathrm{ZnO}$ crystallites and the very thin thickness of the thin film. On the other hand, in the 30layers diagram, we observe the presence of several diffraction peaks. These peaks were assigned to the lines (100), (002), (101), (102), (110), (103) and (112) corresponding to the wurtzite structure of $\mathrm{ZnO}$ and whose space group is $\mathrm{P} 63 \mathrm{mc}$. One can also notice a slight shift in the positions of the diffraction lines compared to those reported in the ASTM file of $\mathrm{ZnO}$. We can observe that the crystalline quality of the thin films improves with the increase in the number of deposited layers [30].

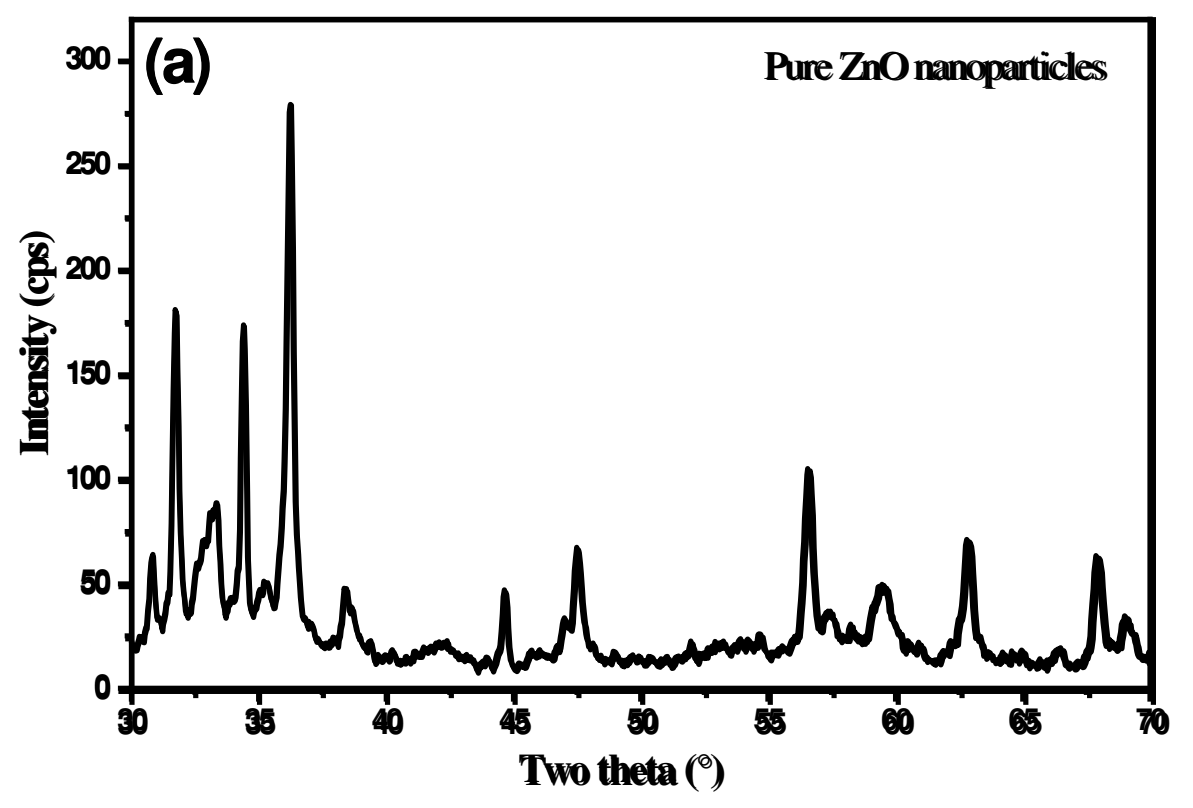




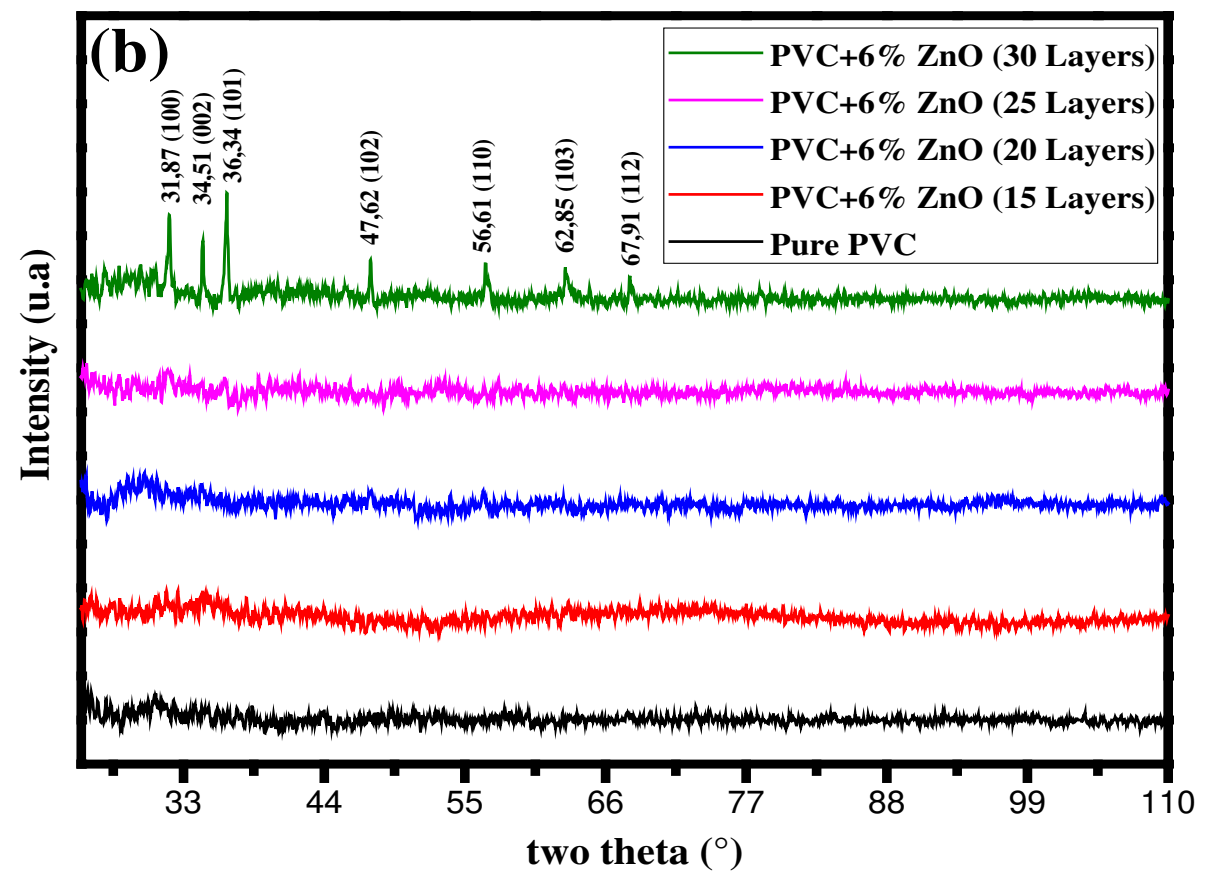

Fig. 1: a XRD pattern of ZnO nanoparticles, $\mathbf{b}$ X-ray diffraction diagram of thin films of pure polyvinyl chloride and doped with $6 \% \mathrm{ZnO}$ crystallites, for the different layers deposited $(15,20,25$ and 30 layers).

The X-ray diffraction results can be used to determine the average crystal size by applying the Scherrer relation to the individual diffraction peaks, given the first approximation that the width of the diffraction lines is primarily due to the crystal size [31].

As for the samples: the first (15 layers), the second (20 layers), and the third (25 layers), we cannot calculate the grain size because the diffraction peaks are not available, but for the fourth sample (30 layers) the average values found are reported in Table 1.

Table 1: the estimated sizes for the $\mathrm{ZnO}$ particles dispersed in PVC

\begin{tabular}{|l|c|c|c|c|c|c|c|}
\hline Reflection & 100 & 002 & 101 & 102 & 110 & 103 & 112 \\
\hline $2 \theta\left(^{\circ}\right)$ & 31,87 & 34,51 & 36,34 & 47,62 & 56,61 & 62,85 & 67,91 \\
\hline FWMH $\left(^{\circ}\right)$ & 0,363 & 0,229 & 0,313 & 0,198 & 0,439 & 0,450 & 0,158 \\
\hline D $(\mathrm{nm})$ & 22,75 & 36,22 & 26,63 & 43,68 & 20,51 & 20,66 & 60,25 \\
\hline$D_{\text {average }}(\mathrm{nm})$ & \multicolumn{7}{|c|}{32,95} \\
\hline
\end{tabular}

\subsection{Raman Spectroscopy Analysis}

Raman spectroscopy was performed at room temperature with laser radiation excitation $(\lambda=632.8 \mathrm{~nm})$.

Figure 2 shows the Raman scattering spectra of the samples developed by the spincoating technique where the spectrum (a) corresponds to the matrix (film) of pure PVC and the spectra (b - e) correspond to the PVC doped with $\mathrm{ZnO}$ crystallites. We note a difference in the appearance of 
the two spectra with the appearance of additive peaks on the spectrum of the doped PVC, so we can say that the doping is successful. The lines located at $360.472,356.671$, and $696.756 \mathrm{~cm}^{-1}$ are common and are due to the PVC, Which is attributed to the vibration of the elongation of the $\mathrm{C}-\mathrm{Cl}$ bond [32]. While the additive lines, due to $\mathrm{ZnO}$ crystallites, are located between 315 to $322 \mathrm{~cm}^{-1}$ and among 422 to $439 \mathrm{~cm}^{-1}$. This result confirms well the X-ray diffraction result on the incorporation of $\mathrm{ZnO}$ crystallites in PVC films.

The wurtzite structure of $\mathrm{ZnO}$ has $\mathrm{C} 6 \mathrm{~mm}$ space group symmetry [33]. The peak located between 422 to $439 \mathrm{~cm}^{-1}$ is due to the $\mathrm{E}_{2}$ (high frequency) mode characteristic of the wurtzite phase of $\mathrm{ZnO}$ [34].

The peak located between 315 to $322 \mathrm{~cm}^{-1}$ corresponds to the vibrational mode due to the multiple phonon process; this vibrational mode indicates that there is a quantum confinement effect in our samples which is due to the very small crystallite sizes of $\mathrm{ZnO}$ [35]. The obtained Raman spectra demonstrate that the $\mathrm{ZnO}$ compound is of the hexagonal wurtzite structure.
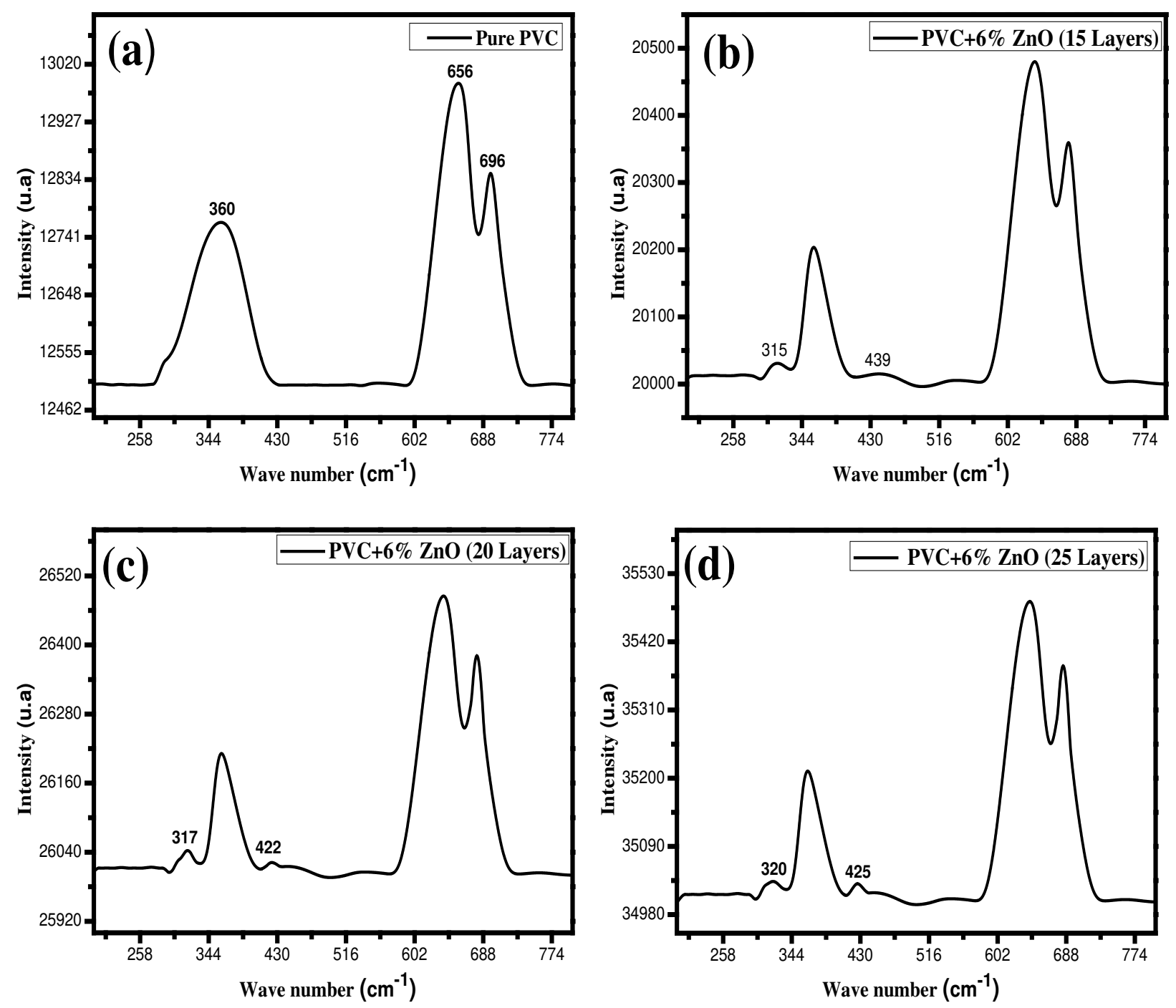


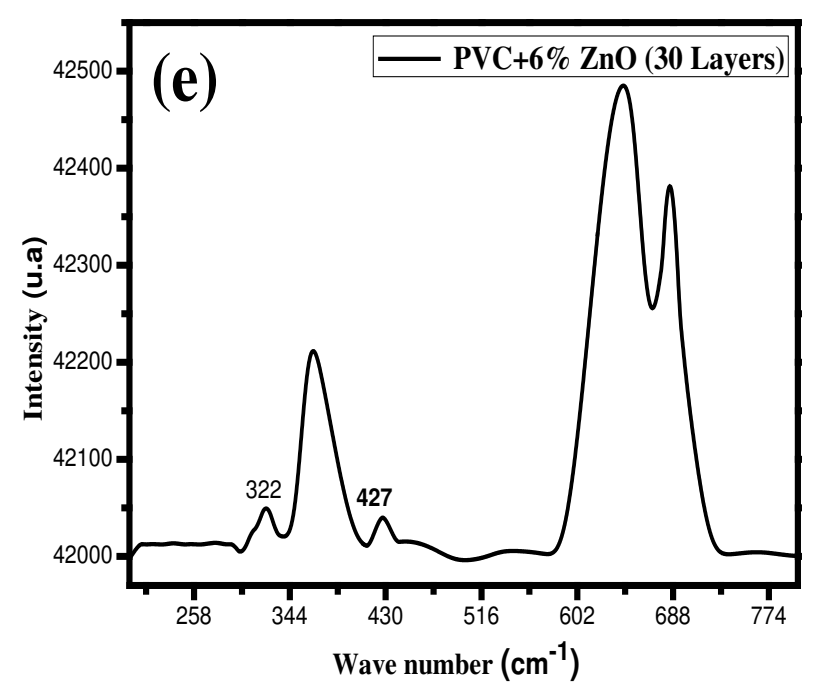

Fig. 2: Raman spectra of a pure polyvinyl chloride film, b-e polyvinyl chloride doped with $6 \% \mathrm{ZnO}$ crystallites, for the different layers deposited (15, 20, 25, and 30 layers).

\subsection{FTIR analysis}

In Figure 3 we can observe the infrared spectra obtained from the pure and doped PVC samples doped with $6 \% \mathrm{ZnO}$ crystallites, for the different layers deposited (15, 20, 25, and 30 layers). They were carried out in the range of the frequencies going from 400 to $2000 \mathrm{~cm}^{-1}$.

The PVC like all polymers is made up of large molecules formed by the repetition of the same unit composed of one or more basic units. The PVC of chemical formula $\left(\mathrm{CH}_{2}=\mathrm{CH}-\mathrm{Cl}\right)$ comprises various types of bonds and thus one observes several bands on the IR spectrum.

The band located at $3215 \mathrm{~cm}^{-1}$ corresponds to the $\mathrm{O}-\mathrm{H}$ bond, and the band $2347 \mathrm{~cm}^{-1}$ is attributed to the $\mathrm{CO}_{2}$ group [36]. The band at $2948 \mathrm{~cm}^{-1}$ is specific to the asymmetric stretch vibration mode $\mathrm{CH}_{2}$. The band at $1701 \mathrm{~cm}^{-1}$ corresponds to the $\mathrm{C}=\mathrm{O}$ bond.

The peak at a higher wavenumber shows the asymmetric stretch bond of $\mathrm{CH}$ and the lower peak corresponds to the symmetrical stretch bond of $\mathrm{CH}$. The peaks around $1400 \mathrm{~cm}^{-1}$ are attributed to the aliphatic flexion bond $\mathrm{CH}$.

The peak at $1250 \mathrm{~cm}^{-1}$ is attributed to the flexion bond of $\mathrm{C}-\mathrm{H}$ near $\mathrm{Cl}$. The stretching bond $\mathrm{C}-\mathrm{C}$ of the chain PVC base is in the range of 1000 to $1100 \mathrm{~cm}^{-1}$. Finally, peaks in the order of $600-650 \mathrm{~cm}^{-1}$ correspond to the left $\mathrm{C}-\mathrm{Cl}$ link [37].

On other spectrums corresponding to doped PVC, there are the same bands but with an additional band confined between 520 and $537 \mathrm{~cm}^{-1}$, it is attributed to a $\mathrm{ZnO}$ mode according to the work of S. J. Jun and A.C. Tas [38,39]. 


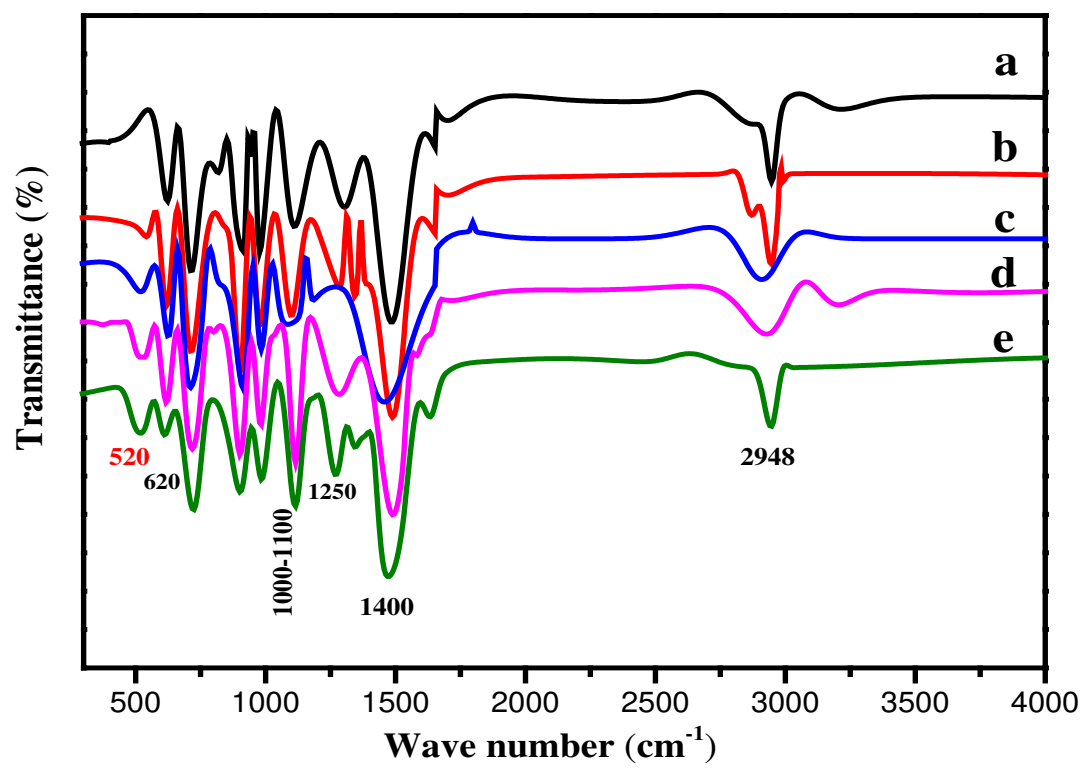

Fig. 3: FTIR spectrum of : a Pure PVC, b PVC doped with 6\%ZnO (15 layers), $\mathbf{c}$ PVC doped with 6\% ZnO (20 layers), d PVC doped with 6\% ZnO (25 layers), e PVC doped with 6\% $\mathrm{ZnO}$ (30 layers).

\subsection{UV-Vis Analysis}

To determine the optical properties of $\mathrm{ZnO} / \mathrm{PVC}$ nanocomposite thin film UV-Vis Spectroscopy was employed. The UV-VIS absorbance spectra in the region 200-900 nm for doped and undoped films are shown in Figure 4. Although the general appearance of the spectra is identical; they are composed of two regions:

A region of high transparency located between 400 and $900 \mathrm{~nm}$, the pure PVC is fully transparent (85\%) and has a steep absorption edge at $300 \mathrm{~nm}$. The transmission value is around 75 to $85 \%$. In this region, we notice a decrease in transmittance with an increase in the number of layers.

A region of high absorption corresponds to the fundamental absorption $(\lambda<400 \mathrm{~nm})$. This absorption is probably due to electron transition from the valence band to the conduction band. The variation in transmission in this region is used to determine the width of the bandgap (optical gap) [40]. 


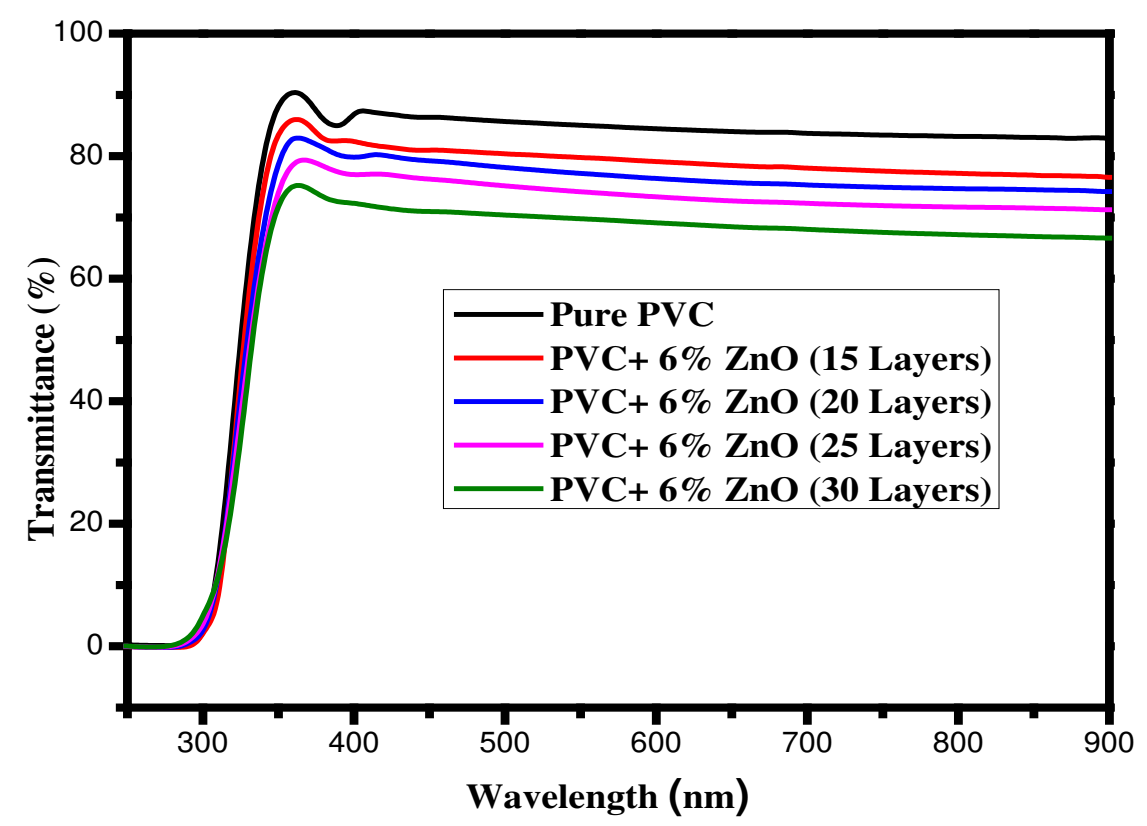

Fig. 4: Optical transmission spectra in the UV-Visible region of Pure PVC, and PVC/ZnO nanocomposites thin films prepared with the different number of layers.

\section{Determination of optical band and thickness}

Tauc' plot method was employed to determine the optical band gap of Pure PVC and $\mathrm{PVC} / \mathrm{ZnO}$ nanocomposites films. Figure 5 shows the Curve $(\alpha h v)^{2}$ as a function of (hv) for a pure PVC film and the samples prepared with the different number of layers $(15,20,25$, and 30 layers) which are linear over a wide range of photon energies indicating the direct type of transitions. The intercepts of these plots (straight lines) on the energy axis give the energy bandgap [41].

The estimated values of Eg listed in Table 2, was obtained by the extrapolation of the straight line to $\alpha=0$. As the number of layers increases, the Eg value decreases from 4.05 to $3.45 \mathrm{eV}$. These band gap value differences of $\mathrm{PVC} / \mathrm{ZnO}$ nanocomposite inform us about the presence of $\mathrm{ZnO}$ crystallites in the PVC matrix and confirm the results obtained previously. 


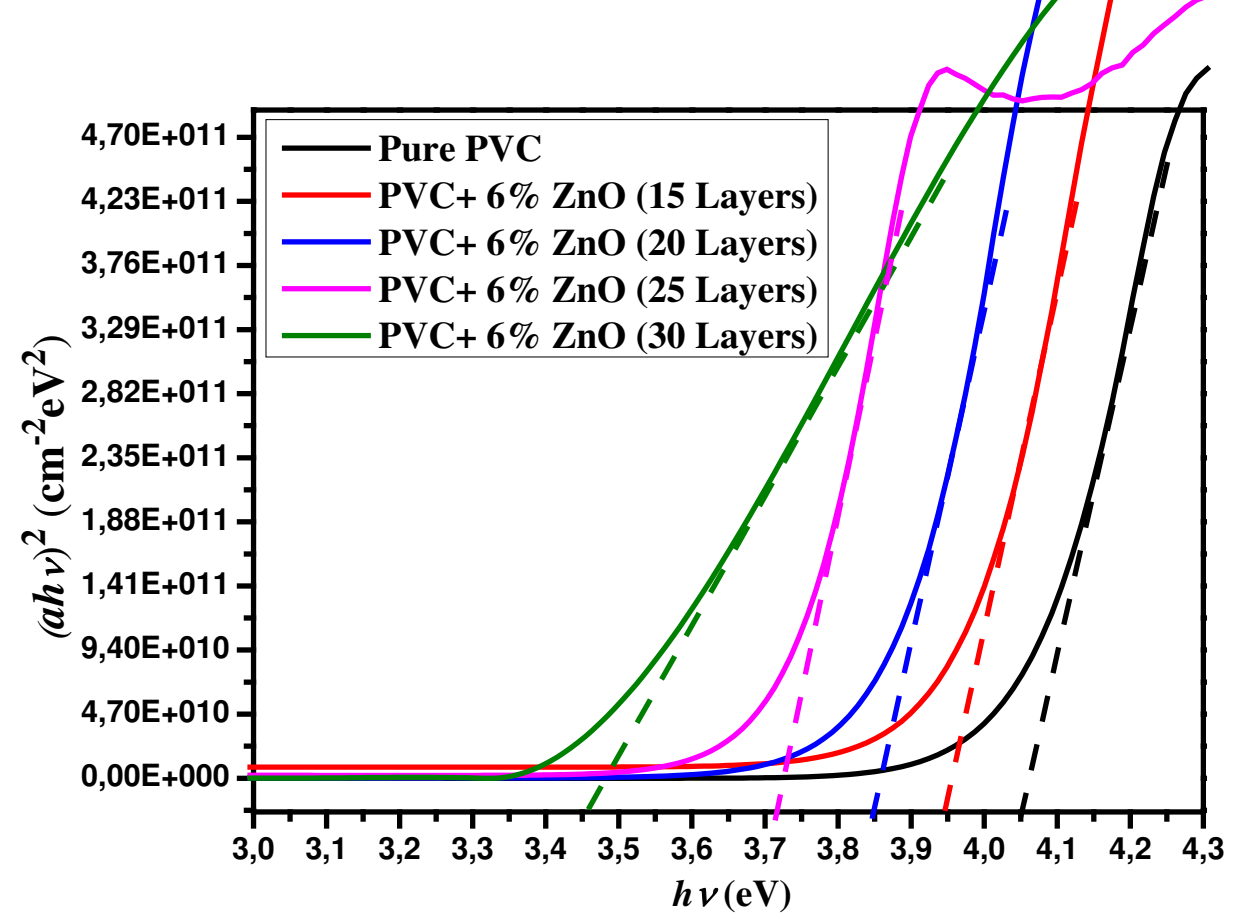

Fig. 5: The plot $(\alpha h v)^{2}$ versus incident energy (hv)

Table 2: gap energy (Eg) of PVC/ZnO nanocomposites thin flms

\begin{tabular}{|c|c|c|c|c|c|}
\hline PVC doped with 6\% ZnO & Pure PVC & 15 Layers & 20 Layers & 25 Layers & 30 Layers \\
\hline Eg (eV) & 4.05 & 3.94 & 3.84 & 3.71 & 3.45 \\
\hline
\end{tabular}

The thickness of the thin layers was determined from the spectrum of the transmittance, using software of "Fit" [42] which allows to vary a certain number of parameters, such as the thickness, the refractive index, and optical gap, and use the least-squares method to adjust a simulated transmittance curve to that measured. Table 3 gives the results of the thickness of our thin layers.

Table 3: Thin layers thickness results

\begin{tabular}{|c|c|c|c|c|c|}
\hline PVC doped with 6\% ZnO & Pure PVC & 15 Layers & 20 Layers & 25 Layers & 30 Layers \\
\hline Thickness $(\mathbf{n m})$ & 109.4 & 133.5 & 146.3 & 182.1 & 220.7 \\
\hline
\end{tabular}

\subsection{Photoluminescence Analysis}

PL spectroscopy is a powerful tool for characterizing the optical quality of semiconductor materials. The intensity of the PL peak corresponds directly to the density of defects in the material. Typically the PL spectrum of $\mathrm{ZnO}$ includes bands in the UV-visible range that correspond to exciton emission.

Figure 6 represents the spectrum of the photoluminescence of a pure PVC film and doped with $\mathrm{ZnO}$ nanocomposites obtained by the spin-coating method, where we notice: 
For pure PVC: One observes, on this spectrum, a weak luminescence centered around 2.86 $\mathrm{eV}$. PVC is therefore a blue light emitter [43-45]. The latter is due to the recombination of the charge carriers after being trapped by gaps or defects of the structure.

For the PVC/ZnO nanocomposite spectra, we observe well-defined peaks, for the PVC samples doped by $\mathrm{ZnO}$ crystallites, whose positions are: $3.24 \mathrm{eV}, 2.72 \mathrm{eV}$, and $2.47 \mathrm{eV}$. The first peak $(3.24 \mathrm{eV})$ is due to phonon emissions from replicas and/or band-to-band recombinations [46]. The second peak $(2.72 \mathrm{eV})$ is attributed to emission from deep levels and/or acceptor-donor recombinations. However, most researchers agree to consider vacant oxygen sites as responsible for this emission $[\mathbf{4 7 , 4 8 ]}$. The mechanism of this emission is as follows: a hole is photogenerated and immediately trapped on a vacant oxygen site (VO). Consequently, a VO is created above the valence band and gives a radiative emission by recombination of the electron with this site. The broadening of this band is due to several factors classified according to the size distribution of the semiconductor crystallites, the environment of the crystallite, and the participation of the electron trapped in and on the surface of the $\mathrm{ZnO}$ crystallites. The band centered at 2.47 $\mathrm{eV}$ corresponds to band-to-band transitions of the semiconductor.

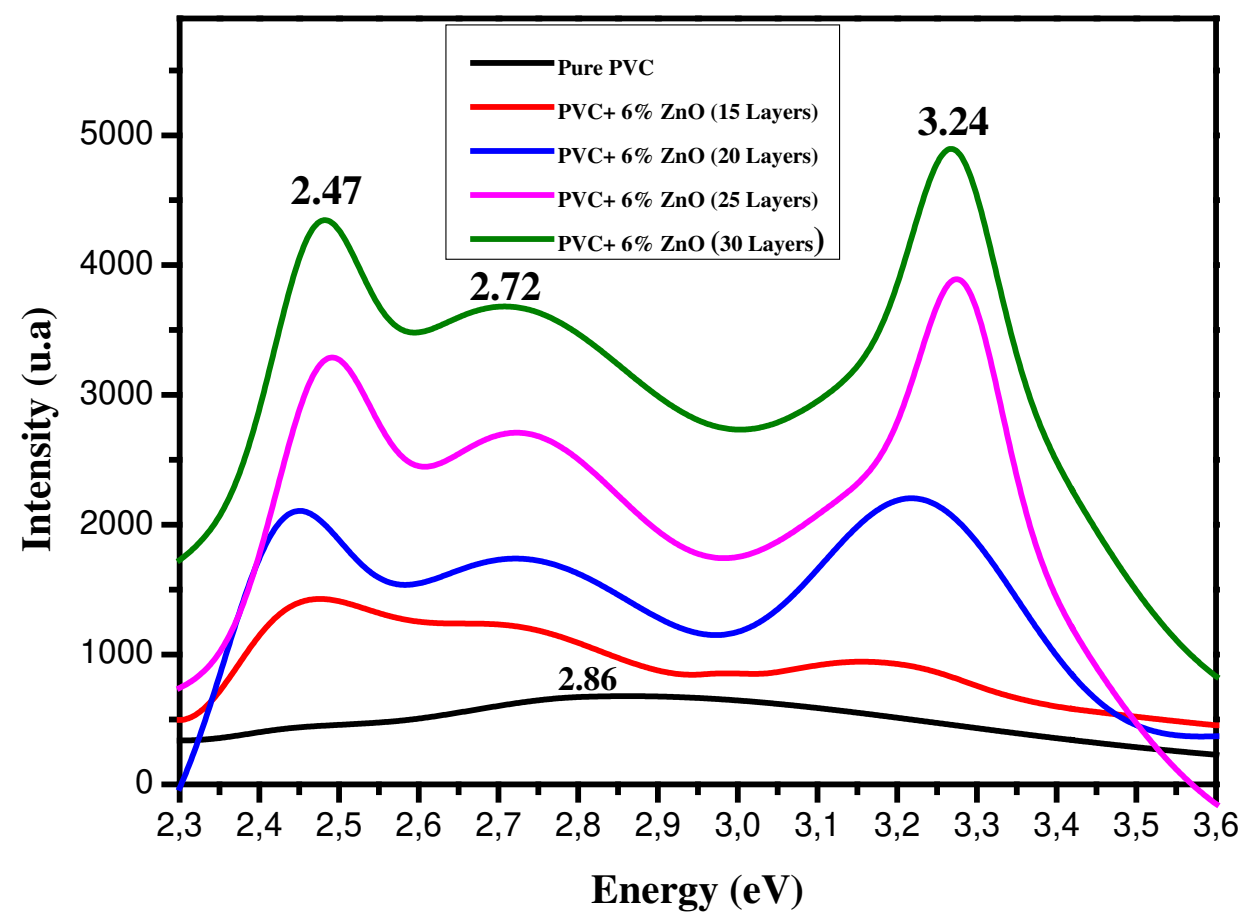

Fig. 6: PL spectra of PVC and PVC doped ZnO nanoparticles. 


\subsection{Photocatalytic Tests}

The photocatalytic activity was studied by the degradation of the methylene blue dye in the presence of PVC / ZnO nanocomposites. Figure 7 shows the evolution of the UV-visible absorption spectra of a methylene blue solution in the presence of thin layers of polyvinyl chloride/zinc oxide with the different number of layers deposited (15, 20, 25, and 30 layers). A UV light source (VL 215.LC, $15 \mathrm{~W}$ ), with an emission maximum at $365 \mathrm{~nm}$ was employed to check the photocatalytic activity of $\mathrm{ZnO} / \mathrm{PVC}$. A cylindrical glass vessel was used containing an aqueous (MB) solution with an initial concentration of $10^{-8} \mathrm{mg} / \mathrm{mL}$. Then, the thin films $\mathrm{PVC} / \mathrm{ZnO}$ nanocomposites on the side were posed into the petri dish, which contains the MB solutions $(10 \mathrm{~mL})$. The beaker was kept under visible light at a distance of $10 \mathrm{~cm}$ emitted by a $300 \mathrm{~W}$ iodine tungsten lamp. During irradiation and after every 10 minutes the aliquots of the solution was taken out and the amount of degradation of the methylene blue dye was measured by the relative intensity of the UV spectra, it was observed that the maximum absorbance peak at $664 \mathrm{~nm}$ decreases continuously in the presence of a catalyst at based on PVC / ZnO nanocomposites, and this decrease increases with the increase in the number of layers deposited, suggesting the degradation of methylene blue.
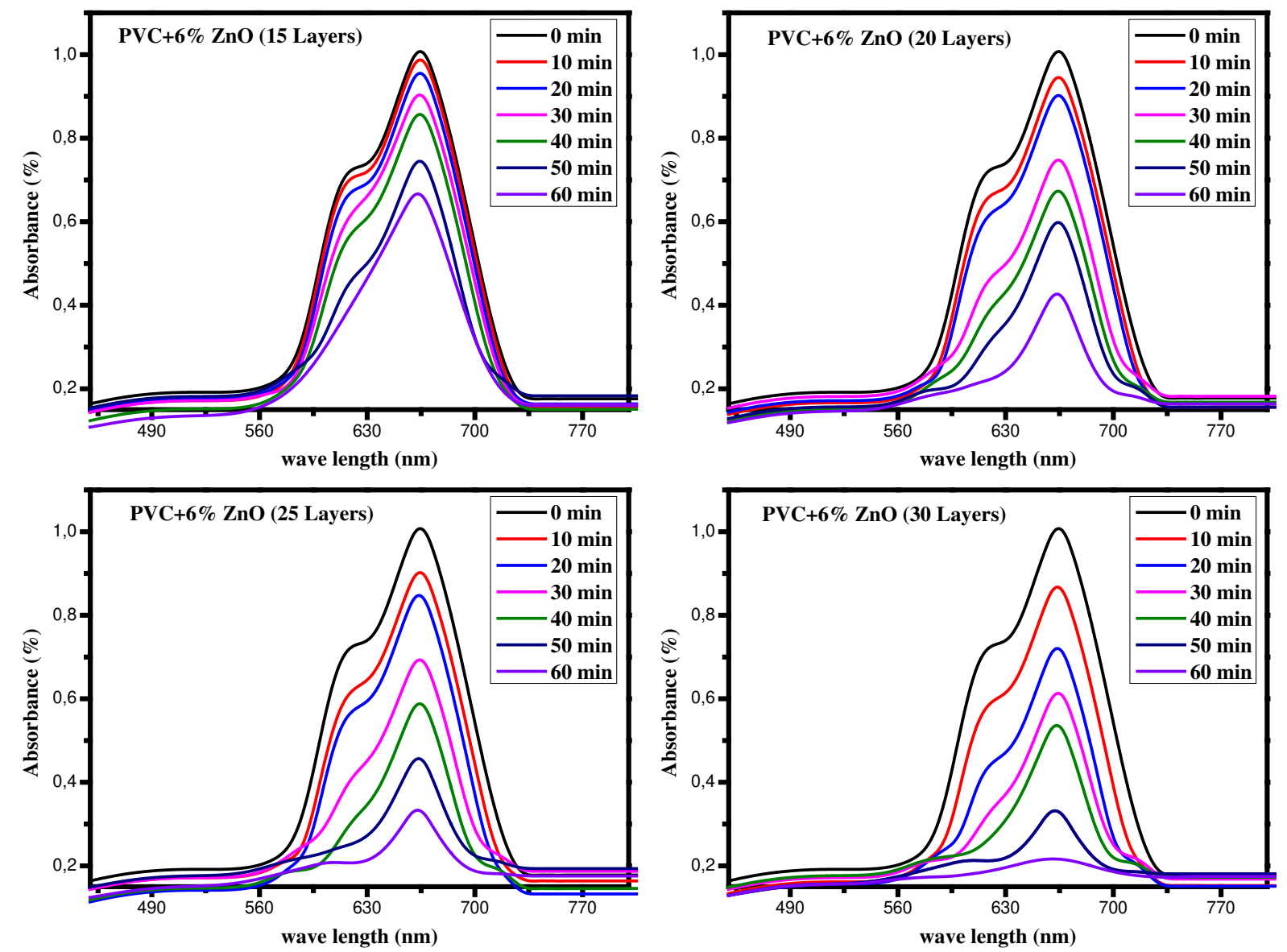

Fig. 7: Evolution of the UV-visible absorption spectra of methylene blue as a function of the time of irradiation with UV light for the various samples prepared. 
Figure 8 represents the variation of $(\mathrm{A} / \mathrm{A} 0)$ as a function of the time, the photocatalytic degradation of a methylene blue solution, and kinetics of methylene blue degradation in the presence of the PVC/ZnO photocatalyst.

In Figure $8 \mathrm{a}$ and $\mathrm{b}$, there is a decrease in the $\mathrm{A} / \mathrm{A} 0$ ratio of the methylene blue solution with an increase of degradation in the presence of $\mathrm{PVC} / \mathrm{ZnO}$ catalyst, this variation shows a significant decrease in the A/A0 ratio for the different catalyst concentrations as a function of time radiation exposure. These results illustrate the photocatalytic properties of zinc stannate in the decomposition reaction of methylene blue. The latter increases with the increase in the number of layers deposited.

In Figure $8 \mathrm{c}$, the variation of $\ln (\mathrm{A} / \mathrm{A} 0)$ as a function of the time of exposure to the rays gives linear curves.

The Dye degradation increase as a function of reaction time under UV light irradiation, which indicates the producing photogenerated electrons $\left(\mathrm{e}^{-}\right)$and holes $\left(\mathrm{h}^{+}\right)$. Because of the potential differences, the LUMO of PVC can transfer to the $\mathrm{CB}$ of $\mathrm{ZnO}$ nanoparticles, whereas the $\mathrm{h}^{+}$in the $\mathrm{VB}$ of $\mathrm{ZnO}$ nanoparticles can transfer to the HOMO of PVC. So the separation of $\mathrm{e}^{-}$and $\mathrm{h}^{+}$in the $\mathrm{PVC} / \mathrm{ZnO}$ nanocomposite can be effectively enhanced, and more $\mathrm{e}^{-}$and $\mathrm{h}^{+}$can be involved in the photocatalytic reactions [49]. Through this, the process of photocatalytic efficiency of samples can be explained with the direct bandgap energy of $\mathrm{PVC} / \mathrm{ZnO}$ nanocomposite which decreased from 4.05 to $3.45 \mathrm{eV}$ as the number of layers was increased from 15 to 30 layers.

The best photocatalytic efficiency is obtained with an almost complete discoloration of the MB solution (79\%) after an irradiation time of $60 \mathrm{~min}$, this is for a 30-layer polyvinyl chloride/zinc oxide sample. The photo-decomposition reaction of $\mathrm{MB}$ follows kinetics of order 1 with a speed constant $\mathrm{k}=0.024 \mathrm{~min}^{-1}$. 

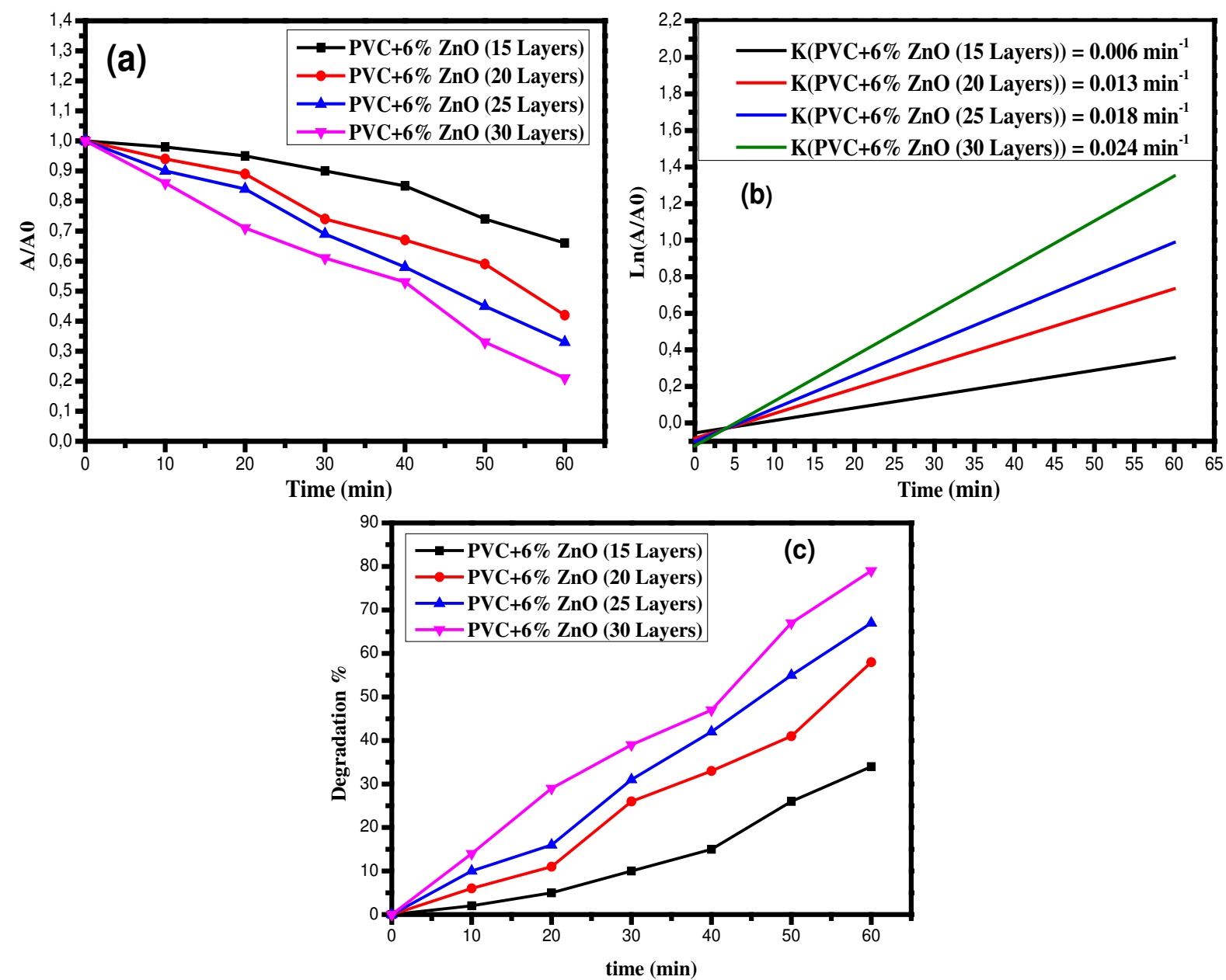

Fig. 8: Decomposition of the dyes (MB) under UV light a A/A0 vs time $b \ln A / A 0$ vs time $c \%$ dye degradation vs time

\section{Conclusion}

In summary, the results indicate that the nanometric zinc oxide $\mathrm{ZnO}$ can effectively boost PVC and improve its structural, optical properties, and photocatalytic activities. The investigations revealed by XRD, Raman and FTIR indicate revealed that $\mathrm{ZnO}$ nanoparticles change their crystalline pure PVC and indicate the dispersion of $\mathrm{ZnO}$ nanoparticles with an average size of $32 \mathrm{~nm}$. The transmission spectra demonstrated that the films PVC/ZnO are transparent in the visible region, where the presence of $\mathrm{ZnO}$ leads to an increase in absorption and a decrease in transmission as the number of layers deposited increases. It has been found that when the number of thin-film layers increases, the thickness of the samples increases, and their optical band gap decreases (3.94$3.45 \mathrm{eV})$. The photoluminescence spectra, at room temperature, carried out from the elaborated samples allowed us to observe intense luminescence bands located in the UV-Visible range. Among these bands, there is one due to the crystallites of the doped $\mathrm{ZnO}$ semiconductor. The application of $\mathrm{PVC} / \mathrm{ZnO}$ nanocomposites of their photocatalysis efficiency is evaluable and consideration. Moreover, these films can be used as an excellent photocatalysis for potential application in the control of environment-friendly photodegradable polymer material. The results of photocatalysis showed that the 30-layer $(\mathrm{PVC} / \mathrm{ZnO})$ sample gave efficiency to remove $\mathrm{MB}$ by $79 \%$ at $60 \mathrm{~min}(\mathrm{k}=$ $\left.0.024 \mathrm{~min}^{-1}\right)$. 


\section{References}

[1] J.W. Gilman, Applied Clay Science, vol. 15, 31-49 (1999).

[2] Y.C. Ou, Z.Z. Yu, A.Vidal et al., Journal of Applied Polymer Science, vol. 59, 1321-1328 (1996).

[3] M. Knite et al., Materials Science and Engineering, vol. C19, 15-19 (2002).

[4] F. Yang, G.L. Nelson, Journal of Applied Polymer Science, vol. 91, 3844-3850 (2004).

[5] M. Wan, J. Fan, Journal of Polymer Science: Part A: Polymer Chemistry, vol. 36, 2799-2805 (1998).

[6] B. Riedl et al., Polymer, vol. 44, pp. 1367-1375 (2003).

[7] P. Hajji, L. David, J.F. Gerard et al.,Journal of Polymer Science: Part B: Polymer Physics, vol. 37, 3172-3187 (1999).

[8] A.J. Nozik,Physica E,Vol.14,115-120(2002).

[9] X. Ma, W. Shi, Microelectronic Engineering,Vol. 66, 153-158 (2003).

[10] P. Alivisatos, Nature Biotechnology, Vol. 22, 47-52 (2004).

[11] M.J.H. Henseler, W.C.T. Lee, P. Miller, S.M. Durbin, R.J. Reeves, Journal of Crystal Growth, Vol. 287, 48-53(2006).

[12] G. Quemard, P. Reiss, S. Carayon, J. Bleuse, Journal of Crystal Growth , Vol. 275, e2395e2402 (2005).

[13] S. Hingorani, V. Pillai, M.S. Multani, D.O. Shah, Materials Reserch Bulletin, Vol. 28, 1303$1310(1993)$.

[14] N. Sankar, K. Ramachandran, Journal of Crystal Growth,Vol. 247, 157-165 (2003).

[15] M.Huang, S. Mao, H. Feick, H. Yan, Y. Wu, H. Kind, E. Weber, R. Russo, P. Yang, Science, Vol. 292,1897-1899 (2001).

[16] U. Ilyas, R. Rawat, G. Roshan, T. Tan, P. Lee, S. Springham, S. Zhang, L. Fengji, R. Chen, Appl Surf Sci, Vol. 258, 890-97 (2011).

[17] A.Ekimov, Physica Scripta, Vol. T 39, 217-222 (1991).

[18] M. G. Bawendi , A.R. Kortan , M. L. Steirgewald, L . E. Brus, Journal of Chemical physics, Vol. 91, 7282-7290 (1989). 
[19] D. J. Norris, Al. L. Efros, M. Rosen, M. G. Bawendi, Physical Review B, Vol.53, 16347- 16354 (1996).

[20] D. J. Norris, M. G. Bawendi, Physical Review B, Vol. 53, 16338-16346 (1996).

[21] V. Albe, Thèse de doctorat, Université Montpellier II (1997).

[22] F. Paille, Thèse de doctorat, Université Claude Bernard, Lyon 1 (1997).

[23] S. Franchi, G. Trevisi, L. Seravalli, P. Frigeri, Progress in Crystal Growth and Characterization of Materials, Vol. 47, 166-195 (2003).

[24] Y. Yang, C. Tran, V. Leppert, S.H. Risbud, Materials Letters, Vol. 43, 240-243 (2000).

[25] B. Boudine, Thèse de doctorat d'état, Université Mentouri de Constantine (2005).

[26] O. Halimi, Thèse de doctorat d'état, Université Mentouri de Constantine (2005).

[27] B. Boudine, M. Sebais, O. Halimi, H. Alliouche, A. Boudrioua, R. Mouras, Catalysis Today, Vol. 89, 293-296 (2004).

[28] B. Boudine, M. Sebais, O. Halimi, R. Mouras, A. Boudrioua, P. Bourson, Optical Materials, Vol. 25, 373-377 (2004).

[29] O. Halimi, B. Boudine, M. Sebais, A. Chelouche, R. Mouras, A. Boudrioua, Materials Science and Engineering C, Vol. 23, 1111-1114 (2003).

[30] S.S. Shariffudin, M. H. Mamat, S.H. Herman, and M. Rusop , IEEE Symposium on Humanities, Science and Engineering Research, 899-902 (2012).

[31] G. Enrico, Thèse doctorat, l’Université Pierre et Marie Curie, France (2004).

[32] A. F. Al Naim, H. AlFannakh, S. Arafat and S. S. Ibrahim, Sci Eng Compos Mater, Vol.27, 55-64 (2020).

[33] L. Spanhel and M.A. Anderson, J. Am. Chem. Soc,Vol. 113, 2826-2833 (1991).

[34] C.A. Arguello, D.L. Rousseau, S.P.S. Porto, Phys. Rev, Vol. 181, 1351-1363 (1969).

[35] V.V. Ursaki, I.M. Tiginyanu, V.V. Zalamai, E.V. Rusu, G.A. Emelchenko, V.M. Masalov, E.N. Samarov, Phys. Rev. B, Vol. 70, 155204 (2004).

[36] R. Moleski, E. Leontidis, F. Krumeich, J. Colloid Interface Sci, Vol. 302, 246-253 (2006).

[37] M. Pandey, G. M Joshi, A. Mukherjeeb and P. Thomasc, Polym.Int, Vol. 65, 1098-1106 (2016). 
[38] S. J. Jun, S. Kim, and J.-H. Han, J. Kor. Ceram. Soc, Vol. 35, 209-218 (1998).

[39] A.C. Tas, P.J. Majewski, and F. Aldinger, J. Am. Ceram. Soc, Vol. 83, 2954-2960 (2000).

[40] I. Ozeroy, D. Nelson, A.V. Bulgakov, W. Marine, M. Sentis, Applied Surface Science ,Vol. 212-213, 349-352 (2003).

[41] M. Caglar, Y. Caglar, S. Ilican,J. Optoelectron. Adv. Mater, Vol. 8, 1410-14130 (2006).

[42] L. Herissi, Doctoral thesis in science, Larbi Ben M'hidi-Oum El Bouaghi University (Algeria) (2016).

[43] H.-J. Lewerenz, Photons in Natural and Life Sciences (Springer,Berlin, 2012).

[44] L. Salasnich, Quantum Physics of Light and Matter (Springer,Padova, 2014).

[45] A. Furusawa, Quantum States of Light (Springer, Padova, 2014).

[46] T. Hirai, Y. Harada, S. Hashimoto, T. Itoh, N. Ohno, J. Lumin, Vol. 112, 196-199 (2005).

[47] H.J. Chang, C.Z. Lu, Y. Wang, C.-S. Son, S.-I. Kim, Y.-H. Kim, I.- H. Choi, J. Korean Phys. Soc, Vol. 45, 959-962 (2004).

[48] M. Shim, P. Guyot-Sionnest, J. Am. Chem. Soc.Vol. 123, 11651-11654 (2001).

[49] G. Nie, G. Li, L. Wang, X. Zhang, Polym. Chem, Vol. 7, 753-769 (2016). 